\section{JSACE 3/16}

The Developments of the Analytical Fragility Methods in Seismic Risk Assessment - A Review

Received 2016/09/24 Accepted after revision 2016/11/07

\section{Introduction}

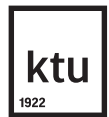

Journal of Sustainable Architecture and Civil Engineering Vol. 3 / No. 16 / 2016 pp. $70-81$

DOI 10.5755/j01.sace.16.3.16500 (C) Kaunas University of Technology

\section{The Developments of} the Analytical Fragility Methods in Seismic Risk Assessment - A Review

\author{
Ahmed Moussa, Petros Christou* \\ Frederick University, 7, Y. Frederickou Str., Pallouriotisa 1036, Nicosia, Cyprus \\ Nicholas Kyriakides \\ Cyprus University of Technology, 2-6 Saripolou, 3603, Limassol, Cyprus
}

*Corresponding author: p.christou@frederick.ac.cy

$\ulcorner$ Grossef http://dx.doi.org/10.5755/j01.sace.16.3.16500

The fragility curves are an essential tool in the seismic assessment of structures and provide a versatile tool to conduct vulnerability analysis for retrofitting and strengthening purposes. The available advancements of computer computational power led to the improvement of the efficiency of the analytical fragility curves. Therefore, this paper focuses on reviewing the recent research developments in the analytical fragility analysis methods. Furthermore, the developments of the intensity and damage measures are presented. In addition, the joint hazards effects on structural fragility are addressed particularly for the environmental degradation and mainshock-aftershock sequence. Finally, recommendations are presented for improving the fragility analysis and highlighting the possible future research areas.

KEYWORDS: Capacity-Spectrum Method, Corrosion, Fragility curves, Incremental dynamic analysis, Mainshock-Aftershock, Seismic risk assessment.

The earthquake devastating effects on the built environment are increasing over the past years in spite of the current efforts and continuous research on seismic design and structural retrofitting. In order to mitigate the losses due to earthquake hazards, it is mandatory to conduct earthquake risk assessments for the existing buildings stock. The earthquake risk assessment is defined as the probability of damages or losses due to earthquakes, which is represented by the fragility curves. The fragility curves represent the probability of exceeding a structural performance level in response to increasing earthquake intensity. The methods used to derive the fragility curves can be grouped into four main categories; empirical, expert elicitation, analytical and hybrid methods.

The fragility curves based on the empirical methods are derived from the observed data after earthquakes. Several researchers developed fragility functions based on extensive surveys for elements that were subjected to earthquake loading. The empirical fragility functions are dependent on the database where the damage data were collected from. In general, the data are obtained either from a single earthquake event or multiple events. The advantage of deriving fragility curves from real observed data is that it accounts for soil-structure interaction (SSI), site 
effects and variation of the structures response and their failure mode. However, the major drawback is that the derived curves are specifically related to a particular area which is characterized by certain soil conditions, earthquake properties, i.e. magnitude, depth, site to source radius, etc., and structural capacity. Furthermore, most of the empirical fragility curves are based on low to medium magnitude events, hence, the curves may provide unreasonable information related to greater magnitudes.

The expert opinion method is totally dependent on the appointed experts who assess the mean loss or the probability of damage for the given elements at risk. Expert elicitations are collected and combined together by two broad approaches; mathematical and behavioral. The method is significantly useful in areas with low real damage data from past earthquakes or in the absence of reliable analytical models. Furthermore, more reliable curves yield when the method is calibrated with the empirical or analytical approaches. Nevertheless, the fragility curves obtained from expert elicitations are only dependent on the experience of the engineer. Moreover, the outcomes of the method are hard to be applied or used in other countries that have different earthquake activity.

The analytical approach is used to obtain the damage distribution through the elements at risk by using numerical methods. The structural systems are modelled and analyzed to establish a relationship between the damage levels and the ground motion at different intensities. Numerical models should be created to find the response of the structures under seismic loads and a choice has to be made between the accuracy and complexity of the models and cost-efficiency of the models. Furthermore, the widely used analytical methods are capacity spectrum method (CSM) and incremental dynamic analysis (IDA). The CSM is a cost-effective method which gives a quick estimation of the structures' response under earthquake loads, however, the actual behavior of the structures may be different. On the other hand, the IDA shows the actual behavior of structures under a suite of ground motions. However, it is a time demanding method depending on the complexity of the models and material type.

The hybrid method utilizes the combination of any two of the methods, which are described above. For example, the analytical models could be calibrated with a real observed data from past earthquakes or from expert judgement data. It is a very effective method since the combination of any two methods should compensate the lack of the other.

There are several analytical approaches for the development of fragility curves that are presented in the literature. However, the most widely used approaches are the CSM and IDA. Hence, the aim of this paper is to review the development and application of both methods in the field of fragility analysis. Additionally, the intensity measures (IM) and damage measures (DM), which are significant parameters in deriving the fragility curves, are also reviewed. Furthermore, besides the hazard from earthquakes, the importance in addressing other hazards in fragility analysis such as environmental degradation and mainshock-aftershock sequence (MS-AS) are addressed.

The earthquake intensity measure (IM) is a significant index that characterizes the ground motion and correlates with the response of each element at risk (e.g. buildings, pipelines, highways, etc.) from the structural engineering point of view. There are numerous IMs that are proposed in the literature and selecting the appropriate IM is a critical task in earthquake risk assessment. In general, the IMs can be classified in two main categories: empirical IM and instrumental IM. The empirical IM are generally used for the derivation of empirical fragility curves that are expressed in terms of macroseismic intensity. The macroseismic intensity scales, e.g. Mercalli-Cancani-Sieberg, Modified Mercalli Intensity etc., are used to quantify the observed damage effects caused by earthquakes. Conversely, the derivation of the analytical and hybrid fragility curves is related to the instrumental IM, e.g. Sa, PGA, PGV, etc. Furthermore, the instrumental IMs are significantly more

Ground
Motion
Intensity
Measure


accurate than empirical IMs and are more representative of the seismic intensity characteristic. It is important to select the most appropriate IM that can sufficiently relate to the chosen damage measure. According to Mackie and Stojadinovic $(2003,2005)$, six features define the optimum IM: practicality, effectiveness, efficiency, sufficiency, robustness and computability.

Practicality simply means that the IM, to some extent, is directly correlated to known engineering quantities such as displacements or rotations. In addition, the practicality of IM can be verified by analyzing the results of a structural response under IDA or time history analysis. A sufficient $\mathrm{IM}$ is the one that is statistically independent from the earthquake magnitude and source-to-site distance (R), Padgett et al. (2008). Furthermore, when the relation between an IM and Engineering demand parameter (EDP) can be evaluated in closed form, it is called effective IM, Mackie and Stojadinovic (2003). The most important and recognized feature is the efficiency which describes the variation in EDP for a given IM. In other words, the dispersion of the calculated seismic demand is less when an efficient IM is used, Shome (1999).

Determining the number of ground motion records which will be used in scaling and IDA is critical in the fragility assessment process. In fact, it affects dramatically the accuracy of the results and the computational time. ASCEISEI 7-10 (2010) recommended that three ground motion records are the minimum and if less than seven are used, the design DM values should be taken as the highest value among the seven records. However, Reyes and Kalkan (2012) argued that ASCEISEI 7-10 procedure is conservative when less than seven records are used. Furthermore, Hancock et al. (2008) concluded that the sufficient number of ground motion records to obtain reasonable results depends on the DM used in the analysis. Moreover, Cimellaro et al. (2011) argued that the use of Sa as IM instead of PGA could reduce the minimum required ground motion records with achieving an accurate estimation of seismic demands.

Seismic Damage Measure
The damage measures (DM) are as important as intensity measures in conducting a fragility analysis. Each damage measure highly affects the shape of the derived fragility curves. In general, the proposed damage measures in the literature can be grouped into three main categories: dynamic parameters of the structure, displacement parameters and displacement and cumulative damage, Kyriakides (2007).

Extensive fragility analysis has been carried out using displacement parameters such as lateral Interstorey drift (ISD), residual drift ratio and Ductility ratio (DR). The commonly used displacement damage indicator is ISD, which is the maximum relative displacement between two storeys normalized to the storey height. Early estimation of ISD threshold values were proposed by Culver (1975) at different damage levels using real damage data observed from damaged buildings. The author suggested that when the ISD value is equal to $h / 100$ or $h / 25$, it corresponds to non-structural damage or severe structural damage, respectively. Several researchers attempted to propose several damage thresholds for ISD, e.g. Elenas (2001), Rossetto (2005) and Nishitani et al. (2015). However, ISD does not provide information about the location of the damage and the residual capacity of the structure. Therefore, it was argued that the residual drift is a significantly important DM parameter in seismic assessment of structures and cost analysis of repair and retrofitting, Tesfamariam and Goda (2015). Hence, it was recommended by several researchers to use residual drift ratios for seismic risk assessment of structures, e.g. Howary and Mehanny (2011), Bojórquez and Ruiz-García (2013) and Ruiz-García and Aguilar (2014). Furthermore, the use of DR, which is the ratio of maximum deformation to yield deformation, was utilized in seismic risk assessment to predict the location of damaged structural elements for the purpose of retrofitting and strengthening, Sfahani et al. (2015).

Nevertheless, the previously mentioned DMs do not consider the cyclic effects of seismic loads due to its dynamic nature. Hence, Park and Ang (1985) developed the most popular DM in dis- 
placement and cumulative damage category, which is shown in Equation 1 that can take into account the effect of low-cycle fatigue and energy dissipation on structural capacity. However, the proposed DM is time and cost demanding because of the need for laboratory or field data to calibrate the constant $\beta$.

$$
D=\frac{\delta_{m}}{\delta_{u}}+\frac{\beta}{Q_{y} \delta_{u}} \int d E
$$

Where:

$\delta_{m}$ Maximum experienced deformation;

$\delta_{u}$ Ultimate deformation;

$Q_{y}$ Yield force;

$\beta$ Constant determined by experimental calibration.

Other similar DMs were proposed and used in the derivation of fragility curves that are mainly suitable for assessing the seismic vulnerability of structures due to mainshock-aftershock sequence as well as investigating the total energy induced by ground motion shaking, e.g. Fajfar (1992), Luco et al. (2004), Bojórquez et al. (2008), Cosenza et al. (2009) and Mander and Rodgers (2013).

The structures' dynamic parameters, i.e. natural frequencies, mode shapes and damping, are used as damage measures by several researchers. In general, by knowing the parameters, they could be used in calibrating the elastic properties for numerical modelling, detecting the structural behavior after retrofitting or damage and predicting its response under earthquake loads, Michel (2008). Bindi et al. (2015) used the ambient vibration to assess the seismic response of an 8-storey reinforce concrete (RC) building which was one of the largest northern Greek hospitals. The natural frequencies and mode shapes of the building were extracted using the peak picking and frequency domain decomposition. It was concluded that the results obtained from the ambient vibration could be used to produce more reliable models based on their existing conditions. Furthermore, Karapetrou et al. (2016) presented a comprehensive methodology for utilizing the obtained field data for a structure, i.e. dynamic properties, in the derivation of time dependent fragility curves. It was the continuation of the work done by Bindi et al. (2015), i.e. the building and its dynamic properties were the same. The monitoring field data and the initial finite element (FE) model were used to form and update a 3D nonlinear FE model, then IDA were performed to derive the time-dependent fragility curves. The 3D FE model took into account the existing structure's conditions such as the strength degradation due to time, possible preexisting damages, changes in geometry or mass distribution, etc.

The analytical approach is used to obtain the damage distribution through the elements at risk by using numerical methods. The structural systems are modelled and analyzed to establish a relationship between the damage levels and the ground motion at different intensities. Two main approaches are used for the analysis which are the capacity spectrum method (CSM) and the incremental dynamic analysis (IDA).

\section{Capacity- Spectrum Method}

The general methodology for the CSM is to perform a static nonlinear pushover analysis, obtaining the pushover curve, which shows the base shear vs the lateral displacement. Then, the pushover curve, also named as the capacity curve, is converted to the capacity-spectrum curve, which is bilinear or multilinear acceleration-displacement curve that describes the structural behaviour when subjected to gravity and lateral loads. The performance point is defined by superimposing the capacity spectrum curve with the earthquake demand curve, i.e. the response spectra. The performance point is the interaction point between the two curves, Freeman (2004). Eventually, after finding the performance point for each seismic intensity, the fragility curves can be constructed. The main advantage of CSM is that it is a reliable simplified static method to used simulate the dynamic behaviour of the seismic events. The CSM was first proposed by Freeman et al. 
(1975), where it was used as a rapid evaluation method to assess the seismic vulnerability of the buildings in Puget Sound Naval Shipyard, Washington. Since introducing the method, it was used in several guidelines and codes. For example, three alternatives for the application of CSM were proposed in ATC-40, namely procedures A, B and C. Procedures B and C were difficult to be used and programed due to the over simplifications considered in procedure $B$ and the extensive graphical components in procedure C. However, procedure A is a simple analytical method and easily applicable in software codes. This method requires an iterative process to reach convergence on the performance point until the demand spectrum intersects with the capacity spectrum within acceptable tolerance. Nevertheless, Fajfar et al. (1999) and Chopra and Goel (2000) criticized the proposed procedure $A$, since it was concluded that it underestimates the structural deformation. Therefore, in FEMA440 modifications had been made to procedure A especially for the part related to the calculation of equivalent viscous damping which is a representation of hysteretic damping. In addition, the Modified Acceleration-Displacement Response Spectrum (MADRS) was introduced to improve the representation of seismic demand by reducing the elastic response spectrum that depends on the increase in ductility and damping. Furthermore, the CSM was adopted in Euro Code 8.

Until today, researchers extensively use the CSM to derive fragility curves for different buildings' typologies. Gencturk and Elnashai (2008) improved the CSM presented in ATC-40 by proposing an advanced CSM that directly incorporates inelastic response history analysis of bilinear systems. Furthermore, the advanced method was validated by conducting a shake-table full-scale test of two timber frame structures. By comparing the obtained results from the tests and the advanced method, it was observed that the proposed method gives more reliable displacement predictions than the existing methods. Nevertheless, it failed to provide reliable predictions for irregular structures. Kyriakides et al. (2014) proposed a framework to conduct a probabilistic seismic vulnerability assessment of low and midrise substandard RC structures, which were designed without seismic codes, based on the modified CSM presented in FEMA440 to consider the degradation in the structural capacity of the substandard structures. The obtained pushover curves of the MDOF structures were converted to equivalent capacity curves of SDOF systems as required by CSM. The buildings' frames were modelled in the software DRAIN 3DX, developed by Prakash et al. (1994), using fiber elements. The models were capable of capturing the gap and pullout effects in hinges and the shear failure in the bonds. Similarly, Ali et al. (2015) adopted Kyriakides et al. (2014) and other researchers to develop vulnerability curves for a typical low engineered structures in Pakistan. DRAIN 3DX was used in the modelling of the two generic 2D frames that are deigned under gravity loads and with insufficient reinforcements. The CSM was used to assess the structural response under the seismic loads. The derived vulnerability curves were compared with empirical vulnerability curves developed by GeoHazards International (GHI). It was concluded that the empirical curves related to Pakistan underestimate the predicted damage for the existing buildings in Pakistan.

Haldera and Paul (2016) investigated the vulnerability of low rise buildings designed for the gravity loads according to the Indian code IS 456 (2000). 2D nonlinear frame elements were modelled in SAP2000 and the CSM was performed according to ATC-40, while the lateral load distribution was given by FEMA 356. Finally, the fragility curves were derived following the HAZUS methodology. Rossetto et al. (2016) presented an innovative approach based on CSM and the use of inelastic response spectra derived from earthquake ground motion accelerograms for the derivation of fragility curves. The proposed method was named Fragility through Capacity Spectrum Assessment (FRACAS). Two four RC frames were used to examine the new method, one was designed without seismic code and the other with seismic code. The main steps of FRACAS are summarized as follows: 
1 The obtained capacity curve is

converted to an idealized trilinear curve.

The idealized trilinear curve is discretized into analysis points, which represents the elastic stiffness, ductility and post-elastic properties of the capacity curve.

3 The performance points (PP) are estimated by intersecting the capacity curve with the 3 spectrum curve using the elastic and inelastic part of the response-spectrum curve, without the need to perform iterations.

The selected engineering demand parameter (EDP) for each PP is determined by finding the corresponding load step of the pushover analysis.

5 The fragility curves are derived through a statistical curve fitting approach from the set of $5 \mathrm{IM}$ and EDP.

The authors compared FRACAS with the nonlinear time history analysis and concluded that the former is reasonably capable of capturing the response of both case studies. Furthermore, the FRACAS was able to account for the record-to-record variability; hence, it was reflected in the derived fragility curves.

\section{Incremental Dynamic Analysis}

The IDA is a nonlinear dynamic analysis method that provides a continuous picture of the structural response under seismic excitations starting from the elastic state, to yielding and finally to collapse. The concept of IDA was proposed by Bertero (1977), nevertheless, it recently became popular and extensively used in fragility and vulnerability analysis. Generally, the IDA procedure involves performing multiple nonlinear time history analysis under a suite of scaled ground motion records that their intensities should be chosen wisely in order to cover the effect of earthquake shakings to structures starting from elasticity to global dynamic instability, Vamvatsikos and Cornell (2002). The curves obtained from IDA, termed IDA curves, show the relationship between the EDP versus IM of the applied scaled ground motion records as shown in Fig. 1. Three components determine the reliability of IDA results, which include the well-established nonlinear structural model, the proper selection of ground motion records and the selection of efficient EDPs and IMs. It is important to select good scaling levels for the ground motion record to ensure reasonable estimates of the distribution of EDP for a given IM provided, that their statistical relationship is effectively independent from the earthquake magnitude and source-to-site distance (R), Vamvatsikos and Cornell (2004). Vamvatsikos and Cornell (2002) argued that the IDA curve produced by a single ground motion record is not enough to define the behavior of a structure. The authors performed IDA on a 5-storey steel braced frame subjected to four different ground motions as shown in Fig. 2. Each curve represents the structural response to the imposed seismic demands. Hence, sufficient number of ground motion records should be included in the analysis. The computational time required to derive fragility curves by IDA is relatively more than CSM. However, the curves derived by IDA are able to capture accurately the seismic response of most of the engineering structures.

Owning to the accuracy of the IDA in capturing the structural behavior and response due to seismic excitations and to the increasing advancement in computers capabilities, the IDA is used extensively in deriving fragility and vulnerability curves for almost all of the engineering structures. For example, Saruddin and Nazri (2015) developed fragility curves for the representing building stock in Malaysia, i.e. RC and steel moment resisting frames. A three story frame representing low-rise and a six story frame representing mid-rise buildings were designed according to Eurocodes 2 , 3, 4 and 8. IDA was performed using the SAP2000 software and a set of seven ground motion records were selected. The ground motion records were scaled by increasing the peak ground 
Fig. 1

IDA curve vs Pushover curve, Vamvatsikos and Cornell (2002)
Fig. 2

Typical IDA curves for a five - storey building under four different earthquakes, Elnashai and Di Sarno (2008)
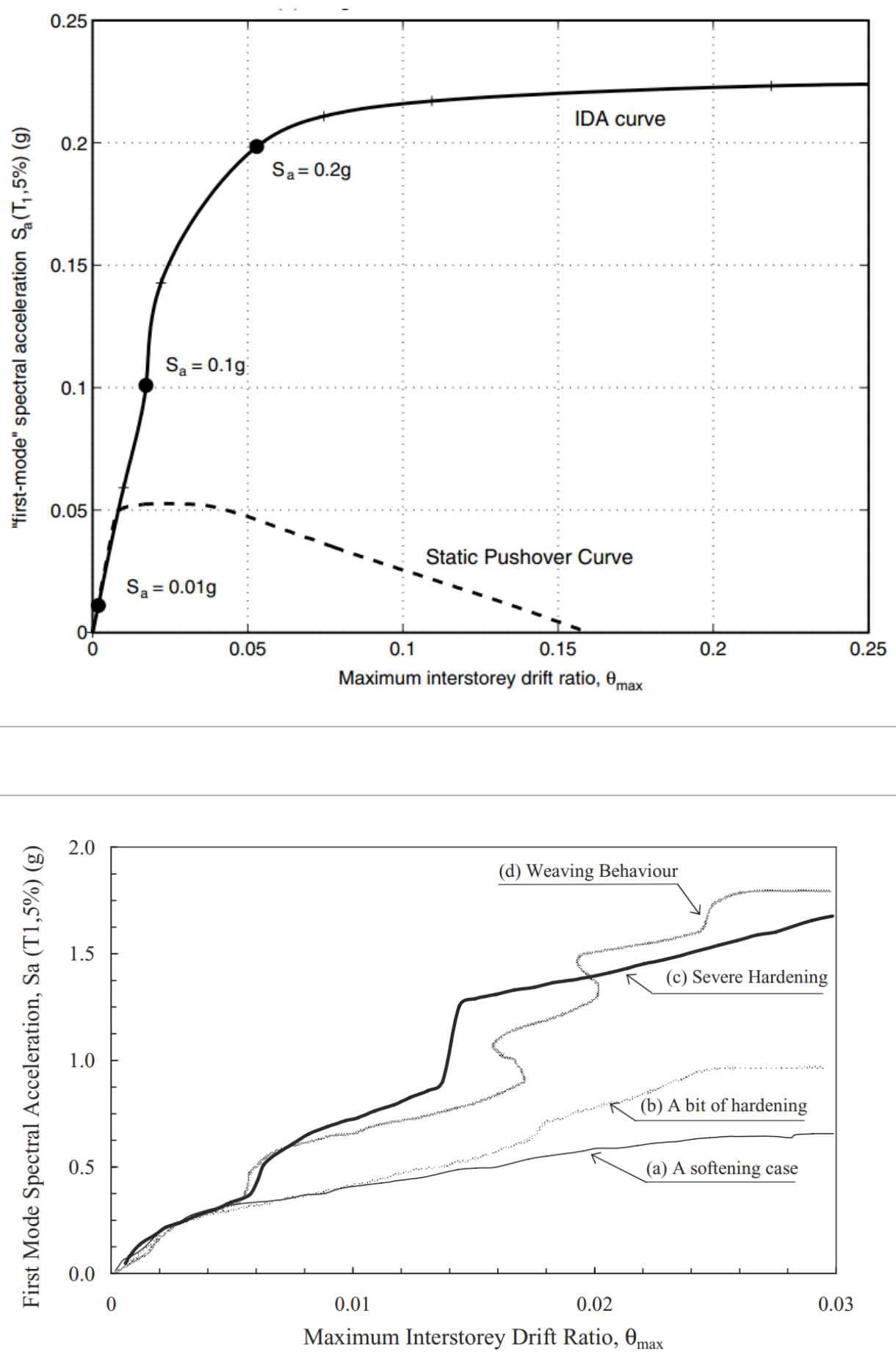

acceleration (PGA) by $0.05 \mathrm{~g}$ until $0.6 \mathrm{~g}$. Finally, several fragility curves were derived to account for the variation in materials and height. Furthermore, Melani et al. (2016) performed seismic risk assessment and financial risk analysis of a low-rise RC frame structure. Three frames were considered in the analysis with the same height, however they were designed differently. The results obtained from the IDA were used in the financial risk analysis, which was expressed in terms of 
the loss ratio. The loss ratio was defined as the cost required to restore the structure to its full working condition to the replacement cost of the structure. Joy and Thampan (2016) investigated the effect of friction pendulum isolation system (FPS) on the seismic vulnerability of a twelve-story RC hospital building located in India. The IDA was carried out to find the structure response under 25 ground motion records. Finally, the fragility curves were developed for the same structure with and without FPS. It was concluded that the FBS reduced significantly the seismic vulnerability of the building because the FBS lengthens the first mode period, which in return reduces the earthquake induced forces. Additionally, Sadraddin et al. (2016) investigated the effect of shear walls' distributions in high-rise buildings on their seismic performance. Four typical twelve story high-rise buildings with the same layout configurations and different shear walls' distributions were designed and analyzed. The IDA was carried out to find the response of the considered case studies under 16 real ground motion pairs. The fragility curves were developed for all the cases. It was observed that installation of shear walls in general improved the seismic performance at all limit states. Nevertheless, the most effective shear walls' configurations appear when the shear walls are placed internally.

It is necessary to include other risk hazards besides the seismic to ensure the safety of the engineering structures during their life cycle. Other hazards could significantly affect the performance of the structures during earthquakes such as the deterioration due to corrosion, soil-structure interaction or the sequence of mainshock and aftershocks. With the current advancement in computers' computational power, it is possible to incorporate theses effects in the fragility analysis of structures in order to know as precisely as possible the real response of structures in future seismic events. Therefore, the effects of corrosion and mainshock-aftershock sequence are presented herein to highlight their significant effects on the performance of engineering structures.

\section{Environmental Deterioration}

In conventional fragility assessment, the impact of environmental deterioration mechanisms (e.g. corrosion, fatigue or cumulative damages from past earthquakes) is not considered. The most pronounced deterioration mechanism for reinforced concrete and masonry structures in the coastal areas is corrosion. Corrosion is a long time-dependent process that causes a significant reduction in the serviceability and vulnerability of RC structures over time Choea et al. (2008). Moreover, the corrosion causes cracking and spalling of concrete, reduction in rebar property and loss in interfacial bond strength. These effects are discussed briefly in the following paragraphs. Zhou et al. (2014) have concluded that cracking of concrete decreases the load bearing capacity of structures as well as shortens their service life. Similarly, the presence of concrete spalling can cause an overestimation of the flexural capacity of RC structures. Furthermore, the quantification of reduction in rebar property is considered by the loss of cross sectional area of the rebar, which could cause a premature fracture before the reach of the rebar's yield limit. Additionally, Kashani et al. (2013) observed that the buckling capacity of the corroded bar was degraded by $20 \%$ due to only 10\% mass loss of the rebar mass. Karapetrou et al. (2013) investigated the impact of corrosion on low and mid-rise RC structures within the framework of REAKT project. It was found that the loss of steel reinforcement cross sectional area due to corrosion ( $t=50$ years) ranged from $24 \%$ to $53 \%$ of the initial cross sectional area. Furthermore, the fragility functions of the corroded low and mid-rise models experienced a considerable increase for the same ground motion compared to the uncorroded models, which proves the effect of environmental deterioration.

Bajaj (2012) showed that the interface bond behavior between the steel and concrete is significantly affected by the corrosion level. It was confirmed, that the bond strength increases due to the increase in corrosion level up to a critical percentage, which depends on the used concrete material, and then decreases. In addition, Kivell (2012) argued that the stiffness reduction of interface

\section{Effect of Joint Hazards on the Fragility of Structures}


bond and its increase in strain penetration due to corrosion raise two critical problems for seismic design and assessment. First, the increased strain penetration induces the concrete members to yield at larger curvatures, reduces steel bar strains at a given curvature and effects energy dissipation. Second, the stability of the whole structure will be reduced with increased P- $\Delta$ effect.

\section{Mainshock-aftershock (MS-AS) effect}

The structures in active seismic areas may experience a sequence of earthquakes because of the Mainshock- aftershock phenomena or other cascade events. As a result, there is no adequate time to repair and retrofit the damages of structures. It has been proven that aftershocks could cause significant damages to structures and increase fatalities and cost, even if the damages from the mainshock are minor. In general, the estimated delay time between a mainshock and the largest aftershock is within the range of several minutes to months. Raghunandan et al. (2015), Han et al. (2014), Li et al. (2014), Nazari et al. (2015). For example, an earthquake with a magnitude of M8.6 struck Indonesia in 2012 followed by several aftershocks, the largest one recorded was with magnitude of M8.2 just after two hours from the main shock USGS (2012). Also, after the mainshock of 2011 Great Tohoku earthquake in Japan, 651 aftershocks were recorded with magnitudes varying from $5 \mathrm{M}$ to $7 \mathrm{M}$ USGS (2011). China has suffered significantly from Wenchuan earthquake with a M7.9 which occurred on May 12, 2008 and followed by 42,719 total aftershocks just within four months after the mainshock. These tremendous aftershocks have considerably increased the number of collapsed buildings, which withstood the mainshock that in return increased the fatalities. In total, the casualties due to the Wenchuan earthquake and its aftershocks were more than 70000 people and the economic loss was estimated as 150 billion U.S. dollars RMS (2008). Similarly, a M7.1 earthquake struck Christchurch, New Zealand on September 4, 2010 and five months later, a M6.3 aftershock struck the city again. This mainshock-aftershock sequence resulted in a toll of 185 deaths and $\$ 15$ billion estimated economic cost, Parker and Steenkamp (2012). Despite the devastating effects of MS-AS sequence, almost all the current seismic assessment or design practice consider the effect of MS only. This lack is attributed to three main reasons; the capacity of damaged buildings after mainshocks, the complexity of the characteristics of aftershocks and their occurrence probability, and a general lack of accurate system fragility models to evaluate building performance, Nazari et al. (2015).

The severity of damages caused by recent earthquakes to the built environment forced the attention of engineers to assess the existing buildings stock and evaluate their vulnerabilities. Therefore, abundance of fragility curves are derived for several civil structures, to predict their response in future earthquake events. The recent significant advancement in the computational power of computers facilitates the use of analytical models and reduces the time required to get the analytical results even for complex nonlinear models. The use of the CSM method provides reasonable results; however, the assumption that the seismic loads are statically distributed over the building does not reflect the actual behavior of structures under seismic excitations. On the other hand, increasing the nonlinear complexity of the materials and models and performing IDA will definitely render the most accurate behavior of structures. It is very important to note that besides the increasing time needed in IDA, the user should have an in depth knowledge about creating detailed models and the appropriate selection of ground motions. Any error related to either one of them could lead to very unrepresentative response of the actual structures. Despite the abundance of the current available fragility curves, relatively few curves are available concerning the combination of fragility analysis with additional hazards probabilities. Furthermore, it was noted that important structural elements such as staircases and lift shafts are not considered in the constructed models. In addition, more research is needed to assess the fragility of the buildings constructed by smart and green materials. 
Ali, M. U., Khan, S. A., Anwar, M. Y., \& Gabriel, H. F. (2015). Probabilistic Application in Seismic Vulnerability Assessment of Deficient Low-to Medium-Rise Reinforced Concrete Buildings in Pakistan. Arabian Journal for Science and Engineering, 40(9), 2479-2486.

ASCE/SEI SEl 7-10 (2010). Minimum Design Loads for Buildings and Other Structures, American Society of Civil Engineers, Reston, USA.

Ashrafi, H., Beiranvand, P., Amiri, A. M., \& Foruzesh, H. (2015). Assessment of concrete by using incremental dynamic analysis method. American Journal of Engineering Research (AJER).

ATC-40. Seismic evaluation and retrofit of concrete buildings. Applied Technology Council: Redwood City, California, USA, 1996.

Bajaj, S. (2012). Effect of corrosion on physical and mechanical properties of reinforced concrete. Ph.D. dissertation, The University of Akron.

Bertero, V.V. ( 1977 ). Strength and deformation capacities of buildings under extreme environments. In Structural Engineering and Structural Mechanics, K.S. Pister , Ed., Prentice - Hall , Englewood Cliffs, NJ, USA, pp. 211 - 215.

Bindi, D., Petrovic, B., Karapetrou, S., Manakou, M., Boxberger, T., Raptakis, D., . . . Parolai, S. (2015). Seismic response of an 8-story RC-building from ambient vibration analysis. Bulletin of Earthquake Engineering, 13(7), 2095-2120.

BIS 456, Indian Standard for Plain and Reinforced Concrete - Code of Practice., Bureau of Indian Standards, New Delhi, 2000

Bojorquez, E., Ruiz, S. E., \& Teran-Gilmore, A. (2008). Reliability-based evaluation of steel structures using energy concepts. Engineering Structures, 30(6), 1745-1759.

Bojrquez, E., \& Ruiz-Garca, J. (2013). Residual drift demands in moment-resisting steel frames subjected to narrow-band earthquake ground motions. Earthquake Engineering $\backslash \&$ Structural Dynamics, 42(11), 1583-1598.

Braga, F., Dolce, M., \& Liberatore, D. (1982). A statistical study on damaged buildings and an ensuing review of the MSK-76 scale. Proceedings of the 7th European Conference on Earthquake Engineering, Athens, 7, pp. 431-450.

Choe, D.-E., Gardoni, P., Rosowsky, D., \& Haukaas, T. (2008). Probabilistic capacity models and seismic fragility estimates for RC columns subject to corrosion. Reliability Engineering $1 \&$ System Safety, 93(3), 383-393.

Chopra, A. K., \& Goel, R. K. (2000). Evaluation of NSP to estimate seismic deformation: SDF systems. References

Cimellaro, G. P., Reinhorn, A., D’Ambrisi, A., \& De Stefano, M. (2011). Fragility analysis and seismic record selection. Journal of structural engineering, 137(3), 379-390.

Cosenza, E., Manfredi, G., \& Polese, M. (2009). Simplified method to include cumulative damage in the seismic response of single-degree-of-freedom systems. Journal of engineering mechanics, 135(10), 1081-1088.

Culver, C., Lew, H., Hart, G., \& Pinkhams, C. (1975). National hazards evaluation of existing building. National Bureau of Standards, US Department of Commerce (January 1975).

EC8 (2004), Design of structures for earthquake resistance-Part 1 General rules, seismic actions and rules for buildings, CEN, Brussels, Belgium.

El Howary, H., \& Mehanny, S. (2011). Seismic vulnerability evaluation of RC moment frame buildings in moderate seismic zones. Earthquake Engineering $\backslash \&$ Structural Dynamics, 40(2), 215-235.

Eleftheriadou, A., \& Karabinis, A. (2008). Damage probability matrices derived from earthquake statistical data. Proceedings of the 14th World Conference on Earthquake Engineering, (pp. 7-201).

Elenas, A., \& Meskouris, K. (2001). Correlation study between seismic acceleration parameters and damage indices of structures. Engineering Structures, 23(6), 698-704.

Elnashai, A. S., \& Di Sarno, L. (2008). Fundamentals of earthquake engineering. Wiley Chichester, UK.

EMA, Pre-standard and Commentary for the Seismic Rehabilitation of Buildings, Report FEMA-356., Federal Emergency Management Agency, Washington D.C, USA, 2000b.

Fajfar, P. (1992). Equivalent ductility factors, taking into account low-cycle fatigue. Earthquake Engineering I\& Structural Dynamics, 21(10), 837-848.

Fajfar, P., \& others. (1999). Capacity spectrum method based on inelastic demand spectra. Earthquake engineering and structural dynamics, 28(9), 979-994.

FEMA/ NIBS methodology (HAZUS ${ }^{\circledR}-M H$ MR5), Advanced Engineering Building Module: Technical and User's Manual, Federal Emergency Management Agency, Washington D.C, USA, 2003.

FEMA-440. Improvement of nonlinear static seismic analysis procedures. Federal Emergency Management Agency, Washington, D.C., U.S.A., 2005.

Freeman, S. A. (2004). Review of the development of the capacity spectrum method. ISET Journal of Earthquake Technology, 41(1), 1-13.

Freeman, S., Nicoletti, J., \& Tyrell, J. (1975). Evaluations of existing buildings for seismic risk--A case study of 
Puget Sound Naval Shipyard, Bremerton, Washington. Proceedings of the 1st US National Conference on Earthquake Engineering, (pp. 113-122).

Gencturk, B., \& Elnashai, A. S. (2008). Development and application of an advanced capacity spectrum method. Engineering structures, 30(11), 3345-3354.

GESI: Global Earthquake Safety Initiative (GESI), Pilot Project. Geohazards International (GHI). UNCRD (2001)

Halder, L., \& Paul, S. (2016). Seismic Damage Evaluation of Gravity Load Designed Low Rise RC Building Using Non-linear Static Method. Procedia Engineering, 144, 1373-1380.

Han, R., Li, Y., \& van de Lindt, J. (2014). Assessment of seismic performance of buildings with incorporation of aftershocks. Journal of Performance of Constructed Facilities, 29(3), 04014088.

Hancock, J., Bommer, J. J., \& Stafford, P. J. (2008). Numbers of scaled and matched accelerograms required for inelastic dynamic analyses. Earthquake Engineering $\backslash \&$ Structural Dynamics, 37(14), 1585-1607.

Karapetrou, S., Fotopoulou, S., \& Pitilakis, K. (2013). Consideration of aging effects on the time-dependent seismic vulnerability assessment of RC buildings. Vienna congress on recent advances in earthquake engineering and structural dynamics.

Karapetrou, S., Manakou, M., Bindi, D., Petrovic, B., \& Pitilakis, K. (2016). "Time-building specific" seismic vulnerability assessment of a hospital RC building using field monitoring data. Engineering Structures, 112, 114-132.

Kashani, M. M., Crewe, A. J., \& Alexander, N. A. (2013). Nonlinear stress--strain behaviour of corrosion-damaged reinforcing bars including inelastic buckling. Engineering Structures, 48, 417-429.

Kivell, A., Palermo, A., \& Scott, A. (2012). Corrosion Related Bond Deterioration and Seismic Resistance of Reinforced Concrete Structures. ASCE/SEI Structures Congress: Chicago, Illinois, USA, (pp. 29-31).

Kyriakides, N. (2007). Vulnerability of RC buildings and risk assessment for Cyprus. Ph.D. dissertation, University of Sheffield.

Kyriakides, N., Ahmad, S., Pilakoutas, K., Neocleous, K., \& Chrysostomou, C. (2014). A probabilistic analytical seismic vulnerability assessment framework for substandard structures in developing countries. Earthq Struct, 6(6), 665-687.

Li, Y., Song, R., \& Van De Lindt, J. W. (2014). Collapse fragility of steel structures subjected to earthquake mainshock-aftershock sequences. Journal of Structural Engineering, 140(12), 04014095.

Luco, N., Bazzurro, P., \& Cornell, C. A. (2004). Dynamic versus static computation of the residual capacity of a mainshock-damaged building to with- stand an aftershock. Proceedings of the 13th world conference on earthquake engineering, 2405.

Mackie K, Stojadinovic B (2003) Seismic demands for performance-based design of bridges. PEER Report 2003/16, Pacific Earthquake Engineering Research Center, University of California, Berkeley, CA

Mackie K, Stojadinovic B (2005) Fragility basis for California highway overpass bridge seismic decision making. PEER Report 2005/12, Pacific Earthquake Engineering Research Center, University of California, Berkeley, CA

Mander, J., \& Rodgers, G. (2013). Cyclic fatigue demands on structures subjected to the 2010-2011 canterbury earthquake sequence. NZSEE Technical Conference and AGM.

Melani, A., Khare, R., Dhakal, R., \& Mander, J. (2016). Seismic risk assessment of low rise RC frame structure. Structures, 5, pp. 13-22.

Michel, C., Guguen, P., \& Bard, P.-Y. (2008). Dynamic parameters of structures extracted from ambient vibration measurements: An aid for the seismic vulnerability assessment of existing buildings in moderate seismic hazard regions. Soil Dynamics and Earthquake Engineering, 28(8), 593-604.

Nazari, N., van de Lindt, J., \& Li, Y. (2015). Quantifying Changes in Structural Design Needed to Account for Aftershock Hazard. Journal of Structural Engineering, 141(11), 04015035.

Nishitani A., Marutani S., Xiang P., Y. Hara, Hatada T., Katamura R., Kanekawa K., Tanii T. (2015) Direct Measurement of Inter-Story Drift Displacements of Scale Model Building in Shake Table Tests, 6th International Conference on Advances in Experimental Structural Engineering.

Padgett, J. E., Nielson, B. G., \& DesRoches, R. (2008). Selection of optimal intensity measures in probabilistic seismic demand models of highway bridge portfolios. Earthquake Engineering $\backslash \&$ Structural Dynamics, 37(5), 711-725.

Park, Y.-J., Ang, A. H.-S., \& Wen, Y. K. (1985). Seismic damage analysis of reinforced concrete buildings. Journal of Structural Engineering, 111(4), 740-757.

Prakash, V., Powell, G. H., \& Campbell, S. (1994). Drain-3DX: Base Program Description and User Guide: Version 1.10. Department of Civil Engineering, University of California.

Raghunandan, M., Liel, A. B., \& Luco, N. (2015). Aftershock collapse vulnerability assessment of reinforced concrete frame structures. Earthquake Engineering $\backslash \&$ Structural Dynamics, 44(3), 419-439.

Reyes, J. C., \& Kalkan, E. (2012). How many records should be used in an ASCE/SEI-7 ground motion scaling procedure? Earthquake Spectra, 28(3), 1223-1242. 
RMS. (2008). “Reconnaissance report: The 2008 wenchuan earthquake: Risk management lessons and implications." Risk Management Solutions, Newark, CA.

Rony Joy, C K Prasad Varma Thampan "Seismic Vulnerability Assesment of Tall RC Building with Friction Pendulum Bearing System", SSRG International Journal of Civil Engineering (SSRG - IJCE), V3(8),1-7 August 2016. ISSN:2348 - 8352. WwW. internationaljournalssrg.org/IJCE/index.html. Published by: Seventh Sense Research Group.

Rossetto, T., \& Elnashai, A. (2005). A new analytical procedure for the derivation of displacement-based vulnerability curves for populations of RC structures. Engineering structures, 27(3), 397-409.

Ruiz-Garca, J., \& Aguilar, J. D. (2015). Aftershock seismic assessment taking into account postmainshock residual drifts. Earthquake Engineering I\& Structural Dynamics, 44(9), 1391-1407.

Sadraddin, H. L., Shao, X., \& Hu, Y. (2016). Fragility assessment of high-rise reinforced concrete buildings considering the effects of shear wall contributions. The Structural Design of Tall and Special Buildings.

Saruddin, S. N., \& Nazri, F. M. (2015). Fragility Curves for Low-and Mid-rise Buildings in Malaysia. Procedia Engineering, 125, 873-878.

Sfahani, M., Guan, H., \& Loo, Y.-C. (2015). Seismic Reliability and Risk Assessment of Structures Based on Fragility Analysis--A Review. Advances in Structural Engineering, 18(10), 1653-1669.

Shome, N. (1999). Probabilistic Seismic Demand Analysis of Nonlinear Structures, PhD Thesis, Stanford University, USA.
Tesfamariam, S., \& Goda, K. (2015). Seismic Performance Evaluation Framework Considering Maximum and Residual Inter-Story Drift Ratios: Application to Non-Code Conforming Reinforced Concrete Buildings in Victoria, BC, Canada. Frontiers in Built Environment, 1, 18.

U.S. Geological Survey (USGS). (2011). "Magnitude 9.0-near the east coast of Honshu, Japan.” (http:// earthquake.usgs.gov/earthquakes/ eqinthenews/2011/usc0001xgp/\#summary) (Apr. 5, 2012). U.S. Geological Survey (USGS). (2012). "Magnitude 8.6-off the west coast of Northern Sumatra." (http://earthquake.usgs.gov/earthquakes/ recenteqsww/Quakes/usc000905e.php\#summary) (Jun. 6, 2012).

Vamvatsikos, D., \& Cornell, C. A. (2002). Incremental dynamic analysis. Earthquake Engineering \& Structural Dynamics, 31(3), 491-514.

Vamvatsikos, D., \& Cornell, C. A. (2004). Applied incremental dynamic analysis. Earthquake Spectra, 20(2), 523-553.

Whitman, R. V., Reed, J. W., \& Hong, S. (1973). Earthquake damage probability matrices. Proceedings of the Fifth World conference on earthquake engineering, 2, pp. 2531-2540.

Yucemen, M., \& Askan, A. (2003). Estimation of earthquake damage probabilities for reinforced concrete buildings. In Seismic Assessment and Rehabilitation of Existing Buildings (pp. 149-164). Springer.

Zhou, Y., Gencturk, B., Willam, K., \& Attar, A. (2014). Carbonation-Induced and Chloride-Induced Corrosion in Reinforced Concrete Structures. Journal of Materials in Civil Engineering, 27(9), 04014245.

\section{AHMED MOUSSA \\ PhD Student \\ Frederick University, Civil Engineering Department, Faculty of Engineering}

\section{Main research area}

Earthquake Engineering; SoilStructure Interaction; Nonlinear Dynamic Analysis

\section{Address}

7, Y. Frederickou Str., Pallouriotisa 1036, Nicosia, Cyprus

E-mail: a.mmmousa@live.com

\section{PETROS CHRISTOU \\ Associate Professor \\ Frederick University, Civil \\ Engineering Department, Faculty of Engineering}

\section{Main research area}

Structural Engineering; Finite Element Analysis; Earthquake Engineering; Nonlinear Analysis

\section{Address}

7, Y. Frederickou Str., Pallouriotisa 1036, Nicosia, Cyprus E-mail: p.christou@frederick.ac.cy

\section{NICHOLAS KYRIAKIDES \\ Post-doctoral Fellow \\ Cyprus University of Technology, Department of Civil Engineering and Geomatics, Faculty of Engineering and Technology}

\section{Main research area}

Seismic assessment of the vulnerability and risk of existing structures; Life cycle assessment using probabilistic methods; Strengthening of existing non seismically designed RC structures; Performance-based design

\section{Address}

Cyprus University of Technology, 2-6 Saripolou, 3603, Limassol, Cyprus E-mail: nicholas.kyriakides@cut.ac.cy

\section{About the authors}

